\title{
Study of Silver Adsorption on Montmorillonite
}

\author{
Petr Praus, ${ }^{* a}$ Martina Turicováa and Marta Valášková ${ }^{b}$ \\ ${ }^{a}$ Department of Analytical Chemistry and Material Testing, VŠB-Technical University of Ostrava \\ 17. listopadu 15, 70833 Ostrava-Poruba, Czech Republic \\ ${ }^{b}$ Nanotechnology Centre, VŠB-Technical University of Ostrava, 17. listopadu 15, 70833 Ostrava-Poruba, Czech Republic
}

\begin{abstract}
Neste trabalho foi estudada a adsorção de $\mathrm{Ag}^{+}$sobre montmorilonita (MMT) do tipo Wyoming rica em $\mathrm{Na}^{+}$. Os dados de adsorção foram ajustados de acordo com várias isotermas comuns, mas os melhores parâmetros de regressão foram obtidos pelo modelo de Langmuir, indicando que $\mathrm{Ag}^{+}$ foi adsorvido na superfície de MMT formando monocamadas. A adsorção de pequenas quantidades de $\mathrm{Ag}^{+}$promoveu o aumento da área superficial específica (SSA) de micro $(\mathrm{r}=0.4-0.5 \mathrm{~nm})$ a mesoporos $(\mathrm{r}=1.5-3 \mathrm{~nm})$. A intercalação de $\mathrm{Ag}^{+}$em MMT foi observada por difração de raios-X (XRD). Com o aumento da concentração de soluções de nitrato de prata, a quantidade de $\mathrm{Ag}^{+}$ em MMT também aumentou e a estrutura em camadas gradualmente sofreu colapso e esfoliação. As amostras de MTT saturadas com $\mathrm{Ag}^{+}$foram tratadas com solução de boro hidreto de sódio para produzir $\mathrm{Ag}^{0}$. Foi estimado um tamanho médio de $\mathrm{L}_{111}=8.5(1) \mathrm{nm}$ dos cristalitos de $\mathrm{Ag}^{0}$. As nanopartículas de prata metálica ficaram localizadas na superfície e nas bordas dos cristais de MMT.
\end{abstract}

In this study $\mathrm{Ag}^{+}$adsorption on $\mathrm{Na}^{+}$-rich montmorillonite (MMT) type Wyoming was studied. Adsorption data were fitted with several common isotherms but the best regression parameters were obtained for Langmuir model. It indicates that $\mathrm{Ag}^{+}$was adsorbed on the MMT surface forming a monolayer. By adsorption of small amounts of $\mathrm{Ag}^{+}$enlargement of the specific surface area (SSA) of micro- $(\mathrm{r}=0.4-0.5 \mathrm{~nm})$ and mesopores $(\mathrm{r}=1.5-3 \mathrm{~nm})$ was found. Intercalation of $\mathrm{Ag}^{+}$into MMT was observed using X-ray diffraction (XRD). With increasing concentration of the silver nitrate solutions the content of $\mathrm{Ag}^{+}$in MMT increased and the layered MMT structure gradually collapsed and exfoliated. The MMT samples saturated with $\mathrm{Ag}^{+}$were treated with the sodium borohydride solutions to produce $\mathrm{Ag}^{0}$. The mean size of the $\mathrm{Ag}^{0}$ crystallites of $L_{111}=8.5(1) \mathrm{nm}$ was estimated. The metal silver nanoparticles are assumed to be located at the layer surface and crystal edges of MMT.

Keywords: adsorption, intercalation, silver, montmorillonite, nanoparticles

\section{Introduction}

Silver is a noble metal with high electrical and thermal conductivity, chemical inertness to oxygen and many other gases and chemicals, photosensitivity to visible, $\mathrm{X}$-ray and gamma-ray wavelengths in the electromagnetic spectrum, and also having catalytic and antibacterial properties. All these features have been widely used in many industrial applications. In the last few years, an effort of many basic research and application research laboratories has been focused on preparation of nanosize particles, which are known for their excellent physical and chemical properties. ${ }^{1}$

*e-mail: petr.praus@vsb.cz
Preparation of silver nanoparticles mostly consists of two steps: Reduction of silver cations mostly from $\mathrm{AgNO}_{3}$ solutions and stabilization of resulting silver nanoparticles. There are several ways of $\mathrm{Ag}^{+}$reduction: for instance, the use of gamma irradiation, ${ }^{2} \mathrm{UV}$ irradiation, ${ }^{3-8}$ femtosecond laser $(800 \mathrm{~nm})$ irradiation, ${ }^{9,10}$ heating of $\mathrm{AgNO}_{3}$ solutions, ${ }^{11}$ electrochemical reduction, ${ }^{12,13}$ application of reducing chemicals $\mathrm{N}_{2} \mathrm{H}_{4},{ }^{14} \mathrm{NaBH}_{4},{ }^{15-17}$ glycerol, ${ }^{18} \mathrm{~N}, \mathrm{~N}$-dimethylformamide, ${ }^{19}$ glucose, ${ }^{20}$ ethylene glycol, ${ }^{21}$ etc.

For the stabilization of silver particles, various chemicals have been used: PAMAM dendrimers, ${ }^{4}$ non-ionic TX-100 micelles, ${ }^{5}$ bis(2-ethylhexyl)-sulphosuccinate reverse micelles,${ }^{14}$ phenylenediamine,${ }^{18}$ linear polyethylenimine, ${ }^{11}$ 
DNA,${ }^{12}$ polyvinylpyrrolidone,,${ }^{3,720}$ nucleobase adenine, ${ }^{17}$ polyvinyl alcohol, ${ }^{2}$ polyethylenphtalate,${ }^{6}$ carboxy methyl cellulose and gelatin, ${ }^{22}$ sodium dodecylsulphate solutions, ${ }^{23}$ amphiphilic block-copolymers, ${ }^{16,24}$ phosphate glass, ${ }^{9}$ etc. Also, the silver particles can be stabilised on surfaces of solids, such as glass surfaces, ${ }^{19} \mathrm{TiO}_{2}{ }^{10}$ phyllosilicates kaolinite, ${ }^{15}$ and montmorillonite. ${ }^{21}$

The two last mentioned papers describe silver reduction on silicates with layered structures (phyllosilicates). Their interlayer spacing serves as a nanoreactor, in which nanoparticles could form. The aim of this work was to investigate the adsorption of silver cations on montmorillonite, which seems to be capable of silver nanoparticles fabrication.

\section{Experimental}

\section{Reagents}

The used chemicals were of analytical reagent grade: silver nitrate, ammonium chloride (Lachema, Czech Republic), sodium borohydride from Merck (Germany). Twice distilled and deionised water by a mixed-bed ionexchanger (Watek, Czech Republic) was used for the preparation of all solutions.

\section{Adsorption procedure}

$\mathrm{Na}^{+}$-rich montmorillonite type Wyoming with exchanged capacity of 0.7 mequiv $\mathrm{g}^{-1}$, determined by saturations with $\mathrm{NH}_{4}{ }^{+}$and by analyses of released metals $\left(\mathrm{Na}^{+}, \mathrm{K}^{+}, \mathrm{Ca}^{2+}, \mathrm{Mg}^{2+}\right)$, was used as the host structure for the absorption of silver cation. The structural MMT formula was $\mathrm{Na}_{0.38} \mathrm{~K}_{0.04}\left(\mathrm{Ca}_{0.12} \mathrm{Mg}_{0.50} \mathrm{Fe}^{3+}{ }_{0.41} \mathrm{Al}_{2.90} \mathrm{Ti}_{0.01}\right.$ $\left.\mathrm{Mn}_{0.01}\right)\left(\mathrm{Si}_{8}\right) \mathrm{O}_{20}(\mathrm{OH})_{4}$ as calculated from the results of chemical analyses. A portion of MMT ( circa $0.1 \mathrm{~g}$ ) was added into $100 \mathrm{~mL}$ of the $\mathrm{AgNO}_{3}$ solutions and these suspensions were shaken vigorously for 24 hours. Then, the suspensions were centrifuged for 20 minutes, filtered, and dried gently at $50^{\circ} \mathrm{C}$ for 24 hours. Supernatants were analysed by means of atomic absorption spectrometry (AAS) using a standardised method. ${ }^{25}$ The room temperature varied from $20{ }^{\circ} \mathrm{C}$ to $24{ }^{\circ} \mathrm{C}$ during all experiments performed in this work. Montmorillonites saturated at the $\mathrm{Ag}^{+}$initial concentrations of $1 \mathrm{mmol} \mathrm{L}^{-1}$, $3 \mathrm{mmol} \mathrm{L}^{-1}, 10 \mathrm{mmol} \mathrm{L}^{-1}$, and $50 \mathrm{mmol} \mathrm{L}^{-1}$ were denoted as samples MMT-Ag1, MMT-Ag3, MMT-Ag10 and MMT-Ag50, respectively.

The content of metallic silver in modified montmorillonite was determined by AAS after dissolution of the MMT samples in a mixture of $\mathrm{HF}$ and $\mathrm{HNO}_{3}$.

\section{X-ray Powder Diffraction}

The X-ray Powder Diffraction (XRD) study was performed using a powder diffractometer (INEL, France) equipped with a curved position-sensitive detector PSD 120 $\mathrm{MB} / 11$ (reflection mode, Ge-monochromatized, $\mathrm{CuK}_{1}$ radiation). Diffraction patterns were taken in ambient atmosphere under constant conditions $(2000 \mathrm{~s}, 35 \mathrm{kV}$, $20 \mathrm{~mA})$.

\section{Specific surface area measurement}

Specific surface area (SSA) of the MMT samples was measured with a Sorptomatic 1990 instrument (Thermo Electron Corporation, USA) using nitrogen as adsorbing gas and calculated by Advance Data Processing software according to BET isotherm at a temperature of 77.31 and at a ratio $\mathrm{P} / \mathrm{P}^{0}$ up to 0.3 , i.e., up to the beginning of capillary condensation. The micro- and mesopore size distributions were calculated by means of Horvath Kawazoe ${ }^{26}$ and Barrett, Joyner, and Halend (BJH) ${ }^{27}$ models, respectively.

\section{Analysis of equilibrium data}

Adsorption isotherms of $\mathrm{Ag}^{+}$were determined through batch experiments. Experimental data were fitted with several isotherms describing monolayer adsorption: Langmuir, Freundlich, Langmuir-Freundlich (Sips), Temkin, and Dubinin-Radushkevich. Non-linear regression was performed by Gauss-Newton iteration method. The best fitting model was chosen according to statistical criteria: regression coefficient (R), Akaike information criterion (AIC), and mean error of prediction (MEP).

\section{Langmuir isotherm}

Langmuir isotherm was theoretically derived supposing that the adsorption takes place on fixed homogenous absorption sites of equal energy, forming a monolayer surface coverage. Langmuir model can be described by the equation

$$
\mathrm{a}=\mathrm{a}_{\mathrm{m}} \frac{\mathrm{bc}_{\mathrm{e}}}{1+\mathrm{bc}_{\mathrm{e}}}
$$

where a $\left(\mathrm{mmol} \mathrm{g}^{-1}\right)$ and $\mathrm{c}_{\mathrm{e}}\left(\mathrm{mmol} \mathrm{L}^{-1}\right)$ are equilibrium concentrations of adsorbate on adsorbent surface and adsorbate concentration in a solution, respectively. The constant $b$ is related to the equilibrium constant, which represents the affinity between adsorbate and adsobent and $\mathrm{a}_{\mathrm{m}}\left(\mathrm{mmol} \mathrm{g}^{-1}\right)$ is the maximum amount adsorbed on the surface. 


\section{Freundlich isotherm}

Freudlich isotherm is strictly an empirical model. The absorbent concentration is a power function of the adsorbate concentration as follows:

$\mathrm{a}=\mathrm{Kc}_{\mathrm{e}}{ }^{1 / \mathrm{p}}$

Unlike Langmuir model, it does not manifest saturation of adsorbent surface. The sorbed amount increases indefinitely with the concentration in the solution. It was found that Freundlich isotherm held for the heterogenous surface when adsorption energy was reciprocal to $\log \Theta$, where $\Theta$ was a $a_{m}$ (a degree of surface coverage). ${ }^{28}$

\section{Langmuir-Freundlich isotherm}

Langmuir-Freundlich (Sips) isotherm is simple generalization of both isotherms mentioned above. It was derived by $\operatorname{Sips}^{29}$ who considered adsorption energy ranging from 0 to $\infty$. It holds for this isotherm:

$$
a=a_{m} \frac{\left(b c_{e}\right)^{p}}{1+\left(b c_{e}\right)^{p}}
$$

where the meaning of symbols is the same as in Langmuir isotherm and $\mathrm{p}$ is the power constant. As this equation has three fitting constants, it much better describes the adsorption including adsorption binding interactions among adsorbing compounds. ${ }^{30}$ For independent noninteracting adsorption sites corresponding to Langmuir model, the value $\mathrm{p}$ is 1 . When $\mathrm{p}>1$, positive cooperativity is assumed, while when $0<\mathrm{p}<1$, negative adsorption cooperativity is expected.

\section{Temkin isotherm}

Temkin isotherm assumes a uniform distribution of adsorption energy, which decreases linearly with the increase of the value $\Theta$. It can be expressed as

$$
\mathrm{a}=\mathrm{a}_{\mathrm{m}}+\mathrm{B} \ln \mathrm{c}_{\mathrm{e}}
$$

where B is Tempkin constant. This model is often used for the description of chemisorption. ${ }^{31}$

\section{Dubinin-Radushkevich isotherm}

Dubinin-Radushkevich isotherm was proposed based on the micropore volume filling theory: ${ }^{32}$

$$
\mathrm{a}=\mathrm{a}_{\mathrm{m}} \mathrm{e}^{-\beta \varepsilon^{2}}
$$

where $\varepsilon$ is Polanyi potential related to the concentration $\mathrm{c}$ as follows

$$
\varepsilon=R T \ln \left(1+\frac{1}{\mathrm{c}_{\mathrm{e}}}\right)
$$

It describes the adsorption on a single type of uniform pores, which is analogical to the monolayer formation. Montmorillonite is considered microporous material and therefore this model was used in this study.

\section{Statistical software}

All statistical calculations were made at the $\alpha=0.05$ significance level by the program QC.Expert 2.5 (Trilobyte Statistical Software, Ltd., Czech Republic).

\section{Results and Discussion}

\section{Adsorption isotherms measurements}

In order to understand the adsorption process of $\mathrm{Ag}^{+}$ on montmorillonite, batch adsorption experiments were performed as described above. The amount of adsorbed $\mathrm{Ag}^{+}$, a (mequiv $\mathrm{g}^{-1}$ ), was calculated as follows:

$$
\mathrm{a}=\frac{\left(\mathrm{c}_{\mathrm{i}}-\mathrm{c}_{\mathrm{e}}\right) \mathrm{V}}{\mathrm{w}}
$$

where $c_{i}$ and $c_{e}$ are the initial and equilibrium $\mathrm{Ag}^{+}$concentrations ( $\mathrm{mmol} \mathrm{L}^{-1}$ ), respectively, $\mathrm{V}$ is volume of the $\mathrm{Ag}^{+}$solutions and $\mathrm{w}$ is mass of MMT. The $\mathrm{Ag}^{+}$equilibrium concentrations were analysed by AAS. From the same solutions, metal cations $\left(\mathrm{Na}^{+}, \mathrm{K}^{+}, \mathrm{Ca}^{2+}, \mathrm{Mg}^{2+}\right)$ were determined by AAS as well. The adsorption data were fitted with the isotherm models described above. The non-linear regression results are given in Table 1. According to the regression criteria R, MEP, and AIC Langmuir and Langmuir-Freundlich isotherms were selected as the most suitable models (Figure 1). In addition, the exponent of Langmuir-Freundlich model $\mathrm{p}=1.0 \pm 0.3$ is statistically equal to 1 , which means that this model can be replaced with Langmuir one. This fact implies that silver cations create a monolayer on the MMT surface. Worse regression parameters of Dubini-Radushkevich isotherm indicate that used montmorillonite contained not only micropores but also a large portion of mesopores.

From Figure 1 it also follows that the concentrations of adsorbed $\mathrm{Ag}^{+}$are lower than those of the desorbed metals, in which sodium prevails (Table 2). The 1:1 ion exchange reaction between $\mathrm{Ag}^{+}$and $\mathrm{Na}^{+}$could be expected in the ideal Na-rich montmorillonite. In our case, the MMT crystallites were mostly delaminated/exfoliated (see below) in the solutions of $\mathrm{AgNO}_{3}$ and thus the MMT solid phase was far 
from its common layered structure. Therefore, silver does not need to occupy the same place, from which sodium is released, and the proportion $\mathrm{Ag}^{+} / \mathrm{Na}^{+}$can differ from 1 . In addition, it is obvious that at the $\mathrm{Ag}^{+}$concentration of about $5 \mathrm{mmol} \mathrm{L}-1$, calcium, strongly fixed to the silicate layers, began to desorb significantly.

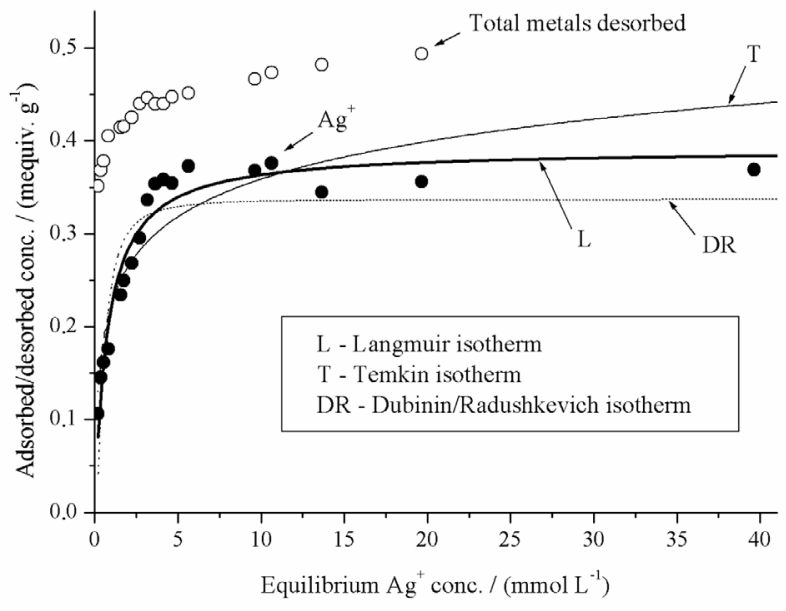

Figure 1. Adsorption of $\mathrm{Ag}^{+}$on montmorillonite and consequent desorption of metal cations.

\section{X-ray Powder Diffraction patterns measurements}

Different basal spacings $d$ observed for the 001 basal diffraction of montmorillonites depend on different interlayer cations and water molecules sorbed in mono or two layers in the interlayer space. For montmorillonites with interlayer occupied by $\mathrm{Na}^{+}$and $\mathrm{K}^{+}, d(001)$ ranges from $1.25 \mathrm{~nm}$ to $1.28 \mathrm{~nm}$ and from $1.19 \mathrm{~nm}$ to $1.22 \mathrm{~nm}$, respectively. ${ }^{33}$

The XRD pattern of MMT (Figure 2a) shows the basal spacing $d(001)=1.26 \mathrm{~nm}$, which corresponds to the prevailing $\mathrm{Na}^{+}$ions in the interlayer (see a crystallochemical formula). Sections of the XRD patterns of MMT-Ag1, MMT-Ag3, MMT-Ag10, and MMT-Ag50 are demonstrated in Figures 2b-e. The profile of the basal 001 diffraction of MMT-Ag1 (Figure 2b) demonstrates the large asymmetric broadening and increase of the interlayer value up to $1.40 \mathrm{~nm}$ documents the intercalation of silver in the MMT interlayer. Decrease of the basal diffraction intensity indicates the partly exfoliated layered structure. If the intensity of the $001 \mathrm{MMT}$ diffraction is express as a relative intensity $\mathrm{I}=100 \%$ then MMT-Ag1 shows the reduced

Table 1. Parameters of the Ag adsorption isotherms

\begin{tabular}{|c|c|c|c|c|c|c|}
\hline Isotherm & $\mathrm{a}_{\mathrm{m}}$ & $\mathrm{k} / \mathrm{K} / \mathrm{B}$ & $\mathrm{p} / \beta$ & $\mathrm{R}$ & $\mathrm{AIC}$ & MEP \\
\hline Langmuir & $0.39 \pm 0.02$ & $1.31 \pm 0.38$ & --- & 0.9755 & -97.4 & 0.00056 \\
\hline Freundlich & --- & $0.23 \pm 0.03$ & $5,61 \pm 1.99$ & 0.9175 & -82.0 & 0.00201 \\
\hline L-F & $0.39 \pm 0.04$ & $1.30 \pm 0.43$ & $1.03 \pm 0.33$ & 0.9768 & -96.1 & 0.00065 \\
\hline Temkin & $0.22 \pm 0.03$ & $0.06 \pm 0.01$ & --- & 0.9533 & -89.2 & 0.00107 \\
\hline D-R & $0.35 \pm 0.02$ & --- & $0.68 \pm 0.26$ & 0.9197 & -82.4 & 0.00184 \\
\hline
\end{tabular}

Note: L-F is Langmuir-Freundlich, D-R is Dubinin-Radushkevich. The number of experimental points used for the non-linear regression was $\mathrm{n}=18$.

Table 2. Percentage balance of the metals desorbed from montmorillonite at the various initial concentrations of the $\mathrm{Ag}^{+}$solutions

\begin{tabular}{lcccc}
\hline Initial Ag conc. $\left(\mathrm{mmol} \mathrm{L}^{-1}\right)$ & $\mathrm{Na}^{+}$desorbed $(\%)$ & $\mathrm{K}^{+}$desorbed $(\%)$ & $\mathrm{Ca}^{2+}$ desorbed $(\%)$ & $\mathrm{Mg}^{2+}$ desorbed $(\%)$ \\
\hline 0.30 & 94.93 & 3.42 & 0.34 & 1.28 \\
0.50 & 94.22 & 4.15 & 0.43 & 1.19 \\
0.70 & 95.08 & 3.60 & 0.30 & 1.06 \\
1.00 & 94.92 & 3.73 & 0.24 & 1.06 \\
1.80 & 94.55 & 4.20 & 0.29 & 1.01 \\
2.00 & 97.73 & 3.95 & 0.38 & 1.04 \\
2.50 & 94.36 & 4.21 & 0.60 & 1.06 \\
3.00 & 93.60 & 4.65 & 0.36 & 1.17 \\
3.50 & 93.42 & 4.93 & 0.57 & 1.32 \\
4.00 & 93.92 & 4.36 & 0.37 & 1.16 \\
4.50 & 93.64 & 4.59 & 0.92 & 1.41 \\
5.00 & 93.23 & 4.40 & 0.99 & 1.45 \\
6.00 & 92.80 & 4.59 & 1.48 & 1.61 \\
10.0 & 90.98 & 4.61 & 2.51 & 2.96 \\
11.0 & 89.61 & 4.58 & 3.69 & 3.32 \\
14.0 & 87.39 & 4.40 & 5.23 & 4.52 \\
20.0 & 85.05 & 4.56 & 9.41 & 5.17 \\
40.0 & 79.23 & 4.64 & & 6.73 \\
\hline
\end{tabular}


intensity of $\mathrm{I}=58 \%$. As the $d(001)$ values increased (Figure $2 b$ ) we could consider the intercalation of $\mathrm{Ag}^{+}$in the MMT interlayer. The line broadening was probably caused by the stress-deformation cracking of the montmorillonite structure forming a lot of smaller crystallites. The first broad peak around $4^{\circ}$ ( 2 theta) was caused by residual water extended the interlayer space of MMT.
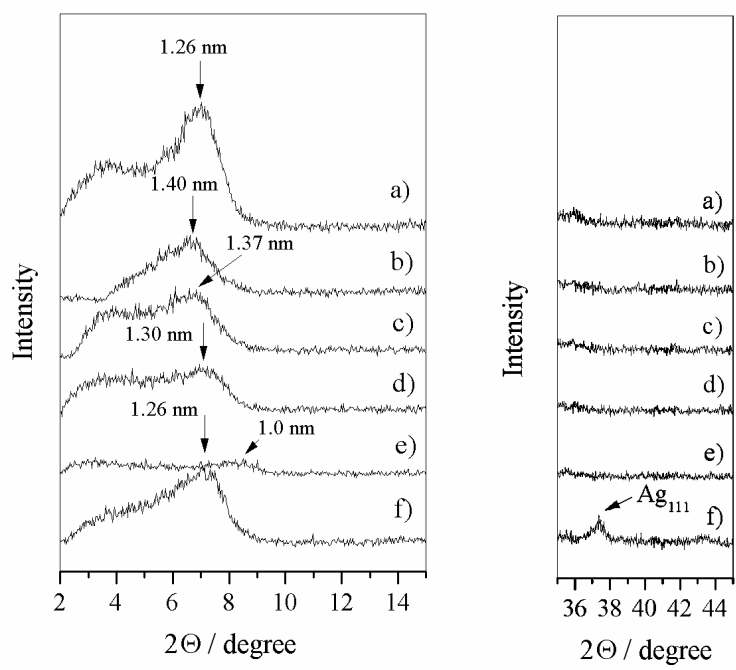

Figure 2. Sections of the powder X-ray diffraction patterns with the region of the first basal diffractions (left side) and the 111 diffraction of metallic Ag (right side): a) MMT, b) MMT-Ag1, c) MMT-Ag3, d) MMT-Ag10, e) MMT-Ag50, f) MMTAg-10red.

Reduction of the 001 line intensity shown in Figures 2c-e proves the gradual collapse of the layered MMT structure. The basal diffraction $d(001)=1.37 \mathrm{~nm}(\mathrm{I}=38 \%)$ of MMT-Ag3 and $d(001)=1.30 \mathrm{~nm}(\mathrm{I}=27 \%)$ of MMT-Ag10 demonstrate decrease of the interlayer spacing and decrease of the peak intensities in comparison with those of MMT-Ag1. Decrease of the $d(001)$ values also reflects the diminished capacity of MMT to adsorb water ${ }^{34}$ due to the ion exchange of the hydrated cations (desorbed metals) with $\mathrm{Ag}^{+}$. The XRD pattern of MMT-Ag50 (Figure 2e) shows definitive exfoliation/ delamination when the layered structure disappears. Residuum of the peak with $d(001)=1.0 \mathrm{~nm}$ indicates diffraction domains probably of silicate layers.

The silver cations in MMT-Ag10 were reduced by sodium borohydride to obtain montmorillonite doped with metallic silver (MMT-Ag10red). Existence of metallic Ag in solid suspensions was proved by the UV-VIS spectra shown in Figure 3. The measured absorbances were caused by absorption and scattering of radiation transmitting through the suspensions. A peak around $\lambda=400 \mathrm{~nm}^{15}$ indicates the presence of $\mathrm{Ag}^{0}$ in the suspensions. By using borohydride in the concentrations of $0.5 \mathrm{mmol} \mathrm{L}^{-1}$, $1.0 \mathrm{mmol} \mathrm{L}^{-1}$, and $10.0 \mathrm{mmol} \mathrm{L}^{-1}$ (see Figure 3), the content of silver decreased at $92.2 \%, 93.7 \%$, and $98.3 \%$, respectively. It means that metallic silver remained in the solid MMT phase whereas the silver cations were removed from the interlayer and crystallised after reduction on the MMT layer surfaces and crystal edges. ${ }^{35}$

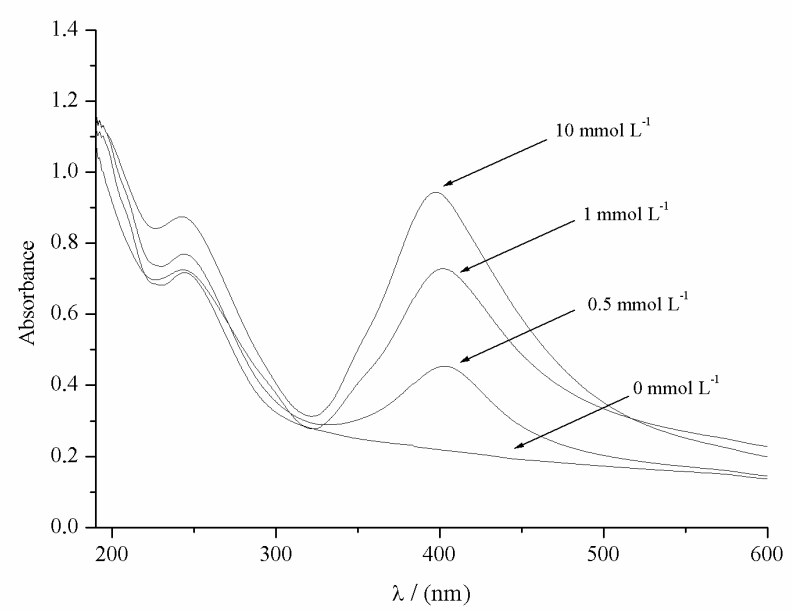

Figure 3. Absorption spectra of metallic Ag reduced by sodium borohydride of different concentrations.

The basal peak 001 of MMT-Ag10red (Figure 2f) with the interlayer value of $d(001)=1.26 \mathrm{~nm}$ and with the higher relative intensity of $\mathrm{I}=65 \%$ in comparison with MMT-Ag10 indicates the sodium intercalation (coming from the $\mathrm{NaBH}_{4}$ solutions) together with restoration of the layer stacking. An additional small peak with maximum at $37.3^{\circ}$ ( 2 theta) in the XRD pattern corresponds to the 111 reflection of $\mathrm{Ag}$ and proves the presence of metallic silver. The average $\mathrm{Ag}$ crystallite size $L_{111}=8.5$ (1) nm was calculated for broadening of the 111 diffraction according to Scherrer equation $L_{111}=\mathrm{k} \lambda / \beta \cos \Theta$, where $\mathrm{k}$ is a constant, $\beta$ is the X-ray diffraction broadening, $\lambda$ and $\Theta$ are the radiation wavelength and Bragg angle, respectively. From the comparison of $L_{111}$ and $d(001)=1.26 \mathrm{~nm}$ of MMT-Ag10red it follows that the metallic silver crystallites have to be located on the layer surface and crystal edges of MMT.

\section{Specific surface area and pore distribution measurements}

Specific surface area of MMT and MMT-Ag were measured by BET method. Nitrogen adsorption and desorption isotherms are demonstrated in Figure 4. Shapes of these curves indicate the presence of slit type micro- and mesopores both in MMT and MMT-Ag. Therefore, Horvath Kawazoe and BJH models were used for the calculations of micro- and mesopore size distributions, respectively. 
Figure 4 also shows that the content of mesopores (indicated by the well visible hysteresis loops) decreased in the following order: MMT-Ag1 > MMT-Ag50 > MMT.

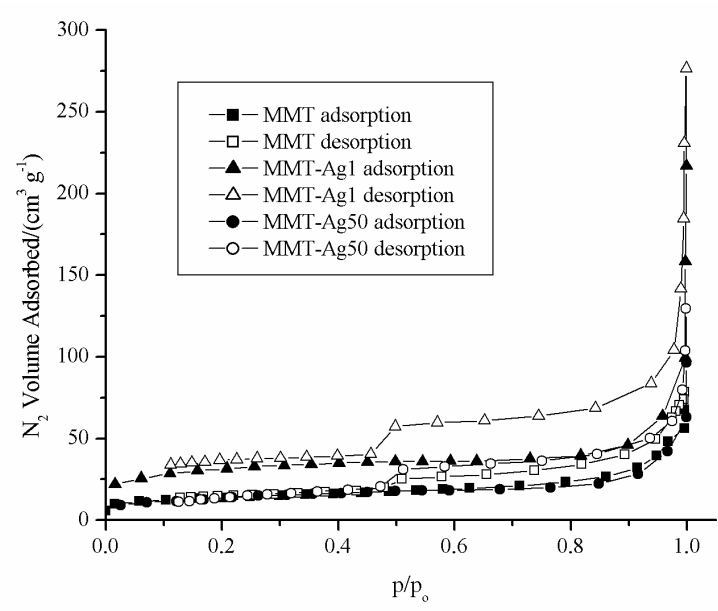

Figure 4. Adsorption and desorption isotherms of $\mathrm{N}_{2}$ on the montmorillonite samples using the BET method.

The SSA values of MMT and MMT-Ag are demonstrated in Figure 5, in which they were plotted against the initial concentrations of $\mathrm{Ag}^{+}$in the adsorption solutions. As obvious, adsorption of the low $\mathrm{Ag}^{+}$concentrations induced sharp enlargement of SSA from $46.7 \mathrm{~m}^{2} \mathrm{~g}^{-1}$ to $112 \mathrm{~m}^{2} \mathrm{~g}^{-1}$. Another increase of the silver concentrations resulted in reduction of SSA at even the lower value $\left(38.9 \mathrm{~m}^{2} \mathrm{~g}^{-1}\right.$ of MMT-Ag100) than original MMT exhibits.

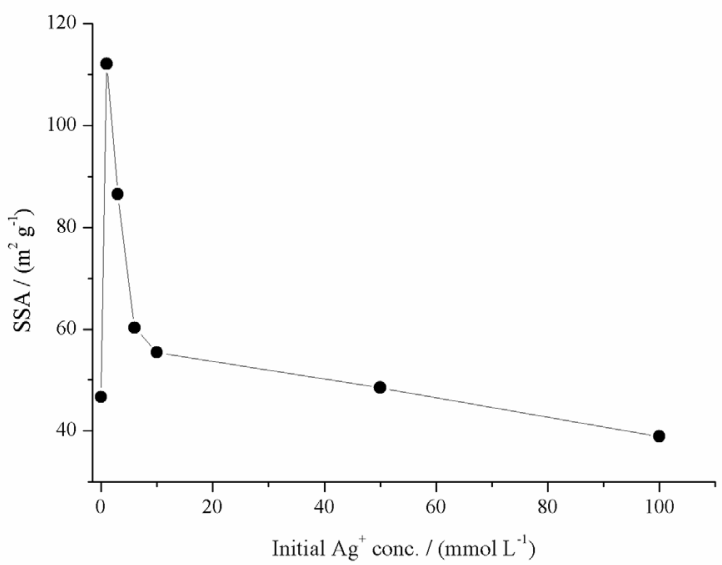

Figure 5. Dependence of the specific surface area on the initial $\mathrm{Ag}^{+}$ concentrations.

These changes can be documented by pore distribution measurements. Figure 6 demonstrates the dependence of SSA on pore radius of MMT, MMT-Ag1, and MMT-Ag50.
Figure 6a shows creation of the pores with radius of $0.2-0.3 \mathrm{~nm}$ and zero SSA of the pores with radius of 0.3-0.4 nm. Another well visible fact is enlargement of SSA corresponding to the pores of $r=0.4-0.5 \mathrm{~nm}$ of MMT-Ag1. Similarly, Figure $6 \mathrm{~b}$ shows high SSA values of the pores with radius of $1.5 \mathrm{~nm}$ to $3 \mathrm{~nm}$. In both cases, the highest SSA values were found in case of MMT-Ag1. In order to understand these phenomena, the XDR patterns of the montmorillonite samples were consulted.
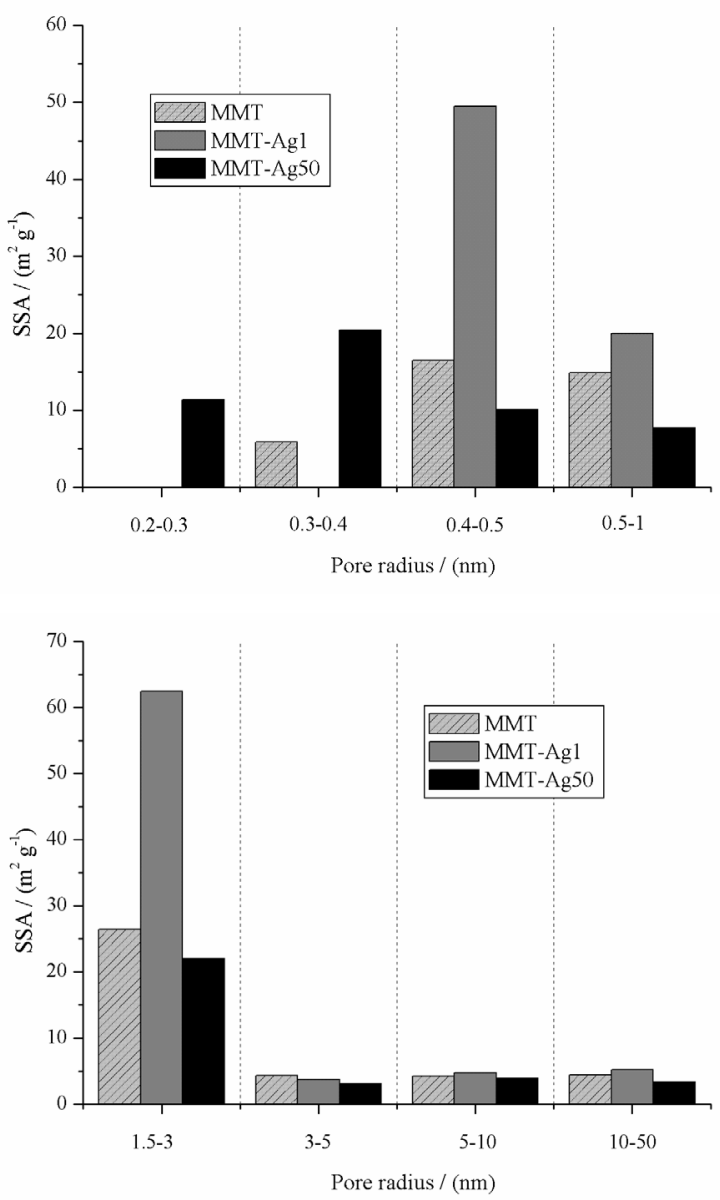

Figure 6. Pore size distribution of micropores (a) and mesopores (b) of the montmorillonite samples.

Pore size distribution changes in comparison with the XRD results

An interesting question arising from the results given above is how to explain the montmorillonite SSA changes caused by the $\mathrm{Ag}^{+}$adsorption. We can suppose two processes, which take place during the intercalation. i) At the low concentrations of $\mathrm{Ag}^{+}$(Figure $2 \mathrm{~b}$ ), the smaller crystallites are created. Consequently, SSA of micropores $(r=0.4-0.5 \mathrm{~nm})$ and mesopores $(r=1.5-3 \mathrm{~nm})$ and thus total SSA of 
montmorillonite enlarge. ii) At the higher concentrations of $\mathrm{Ag}^{+}$(Figures 2c-e), the progressive intercalation is followed by delamonation/exfoliation and thus reduction of the interlayer content of water. Therefore, SSA of modified montmorillonite decreases. In addition, very narrow galleries between the MMT layers corresponding to $d(001)=1.0$ originate as indicated by new micropores $(\mathrm{r}=0.2-0.3 \mathrm{~nm})$ of MMT-Ag50 (Figure 6a). The other SSA changes are supposed to be within experimental errors of BET method and that is why they are not more discussed here.

\section{Conclusions}

The silver cations form a monolayer on the MMT surface and their adsorption can be described by Langmuir isotherm. Part of $\mathrm{Ag}^{+}$was intercalated into the MMT interlayer, which was demonstrated by changes of the 001 diffraction peaks and the SSA values. At low concentrations of $\mathrm{Ag}^{+}$, the MMT crystallites disintegration caused the SSA enlargement. Further increase of the $\mathrm{Ag}^{+}$ concentrations caused the significant interlayer cations exchange and following decrease of the interlayer water content. Therefore, the MMT interlayer space was reduced as indicated by the decrease of SSA.

Reduction of adsorbed $\mathrm{Ag}^{+}$using sodium borohydride recovered the layered structure by the ion exchange with $\mathrm{Na}^{+}$ and by removal of silver from the interlayer on the layer surface and crystal edges of MMT. Existence of the $\mathrm{Ag}^{0}$ crystallites was proved by the presence of the 111 peak in the XRD patterns and by the absorption bands around $400 \mathrm{~nm}$ in the UV-VIS spectra. The crystallite mean size $L_{111}=8.5 \mathrm{~nm}$ of $\mathrm{Ag}^{0}$ was calculated according to Scherrer equation.

Our next research will be focused on the phyllosilicateassisted preparation of the silver metal nanoparticles using various reduction agents. Application of the phyllosilicatesilver composite materials in various fields, such as the water disinfection, catalysis, etc., will be investigated as well.

\section{Acknowledgment}

The authors thank Mrs. S. Študentová (Department of Analytical Chemistry and Material Testing, VSB-Technical University of Ostrava) for measurements of porosity and specific surface areas. This work was supported by the Ministry of Education, Youth and Sport of the Czech Republic (MSM 6198910016).

\section{References}

1. Cao, G.; Nanostructures and Nanomaterials: Synthesis, properties and applications, Imperial College Press: London, 2004.
2. Temgire, M. K.; Joshi, S. S.; Rad. Phys. Chem. 2004, 71, 1039.

3. Huang, H. H.; Ni, X. P.; Loy, G. L.; Chew, C. H.; Tan, K. L.; Loh, F. C.; Deng, J. F.; Xu, G. Q.; Langmuir 1996, 12, 909

4. Keki, S.; Török, J.; Deák, G.; Dároczi, L.; Zsuga, M.; J. Colloid Inter. Sci. 2000, 229, 550.

5. Ghosh, S. K.; Kundu, S.; Pal, T.; Bull. Mater. Sci. 2002, 25 , 581.

6. Kang, S. W.; Kim, J. H.; Ko, D.; Kim, C. K.; Won, J.; Char, K.; Kang, Y. S.; J. Polym. Sci.: Part B: Polym. Phys. 2004, 42, 3344.

7. Yang, X.; Lu, Z.; Mater. Lett. 2005, 59, 2484.

8. Shao, K.; Yao, J.; Mater. Lett. 2006, 60, 3826.

9. Zhao, Q. Z.; Qiu, J. R.; Jiang, X. W.; Zhao, C. J.; Zhu, C. S.; Optics Express 2004, 12, 4035.

10. Zeng, H.; Zhao, C.; Qiu, J.; Yang, Y.; Chen, G.; J. Crystal Growth 2007, 300, 519.

11. Sun, X.; Luo, Y.; Mater. Lett. 2005, 59, 3847.

12. Zhu, J.; Liao, X.; Chen, H. Y.; Mater. Res. Bull. 2001, 36, 1687.

13. Plieth, W.; Dietz, H.; Anders, A.; Sandmann, G.; Meixner, A.; Weber, M.; Kneppe, H.; Surface Sci. 2005, 597, 119.

14. Zhang, W.; Qiao, X.; Chen, J.; Wang, H.; J. Colloid. Inter. Sci. 2006, 302, 370.

15. Patakfalvi, R.; Oszkó, A.; Dékány, I.; Colloids and Surfaces A, Physicochem. Eng. Aspects 2003, 220, 45.

16. Ishizu, K.; Furakawa, T.; Yamaha, H.; Europ. Polym. J. 2005, $41,2853$.

17. Wei, H.; Li, J.; Wang, Y.; Wang, E.; Nanotechnology 2007, 18, 175610 .

18. Ullah, M. H.; Il, K.; Ha, C. S.; Mater. Lett. 2006, 60, 1496.

19. Pastoriza-Santos, I.; Liz-Marzán, L. M.; Pure Appl. Chem. 2000, $72,83$.

20. Wang, H.; Qiao, X.; Chen, J.; Wang, X.; Ding, S.; Mater. Chem. Phys. 2005, 94, 449.

21. Ayyappan, S.; Subbanna, G. N.; Goplan, R. S.; Rao, C. N. R.; Solid State Ionics 1996, 84, 271.

22. Kapoor, S.; Langmuir 1998, 14, 1021.

23. Yonezawa, Y.; Sato, T.; Kuroda, S.; Kuge, K.; J. Chem. Soc., Faraday Trans. 1991, 87, 1905.

24. Wang, L.; Chen, X.; Zhao, J.; Sui, Z.; Zhuang, W.; Xu, L.; Yang, C.; Colloids Surf., A 2005, 257, 231.

25. Analytical Methods for Flame Spectrometry, Varian Techtron Pty. Ltd.: Springvale, 1979.

26. Horwath G.; Kawazoe K.; J. Chem. Eng. Japan 1983, 16, 470.

27. Barrett, E. P.; Joyner, L. G.; Halenda, P. P.; J. Am. Chem. Soc. 1951, 73, 373.

28. Halsey, G.; Advan. Catal. Relat. Subj. 1952, 4, 259.

29. Sips, R.; J. Chem. Phys. 1950, 18, 1024.

30. Sharma, S.; Agarwal, G. P.; Anal. Biochem. 2001, 288, 126. 
31. Moore, W. J.; Physical Chemistry, $4^{\text {th }}$ ed., Prentice-Hall: New Jersey, 1972.

32. Dubinin, M. M.; Prog. Surface Membrane Sci. 1975, 9, 1.

33. MacEwan, D. M. C.; Wilson, M. J.; In: Crystal structures of Clay Minerals and their X-ray identification; Brindley, G. W.; Brown, G. eds.; Mineralogical Society London, 1980, pp. 193-248.
34. Wu, J.; Low, P. F.; Roth, C. B.; Clays Clay Min. 1989, 37, 211.

35. Valášková, M.; Martynková, G. S.; Lešková, J.; Čapková, P.; Klemm, V.; Rafaja, D.; J. Nanosci. Nanotechnol. 2007, 8, 1.

Received: August 27, 2007 Web Release Date: March 14, 2008 